\title{
Clinical variants of idiopathic torsion dystonia
}

\author{
STANLEY FAHN \\ From the Dystonia Clinical Research Center, Department of Neurology, Columbia University College of \\ Physicians \& Surgeons and The Neurological Institute of New York, Presbyterian Hospital, New York, USA
}

SUMMARY Some patients with dystonic movements and postures not known to be caused by environmental or degenerative disorders can be segregated from classical-appearing idiopathic torsion dystonia on the basis of distinctive clinical and pharmacologic features. Many of them should be considered within the family of dystonia, as clinical variants of idiopathic torsion dystonia, while others are better classified as being part of other families of dyskinesias. In the former group are paradoxical dystonia, myoclonic dystonia, diurnal dystonia, and dopa-responsive dystonia. The latter group consists of dystonic tics and the various entities comprising paroxysmal dystonia, namely kinesigenic, nonkinesigenic and hypnogenic dystonia.

Classical idiopathic dystonia

The terms dystonia and torsion dystonia are used interchangeably and refer both to the syndrome classically described by Oppenheim' ${ }^{\prime}$ and by Flatau and Sterling ${ }^{2}$ in 1911 and to the types of abnormal involuntary movements and postures found in this syndrome. The abnormal movements making up dystonia are diverse, with a wide range in speed, amplitude, rhythmicity, torsion, forcefulness, distribution in the body, and relationship to rest or voluntary activity. ${ }^{3}$ Despite such variety, two features of dystonic movements are distinctive, the contractions are sustained at the peak of the excursion, and the contractions are repetitive and are typically torsional. Clinical syndromes manifesting such types of abnormal movements are therefore dystonic states, whether idiopathic (primary) or symptomatic (secondary). Currently, dystonic states are defined as syndromes of sustained muscle contractions, frequently causing twisting and repetitive movements, or abnormal postures. ${ }^{4}$

Other features that are highly characteristic of dystonia, but are not essential to the diagnosis, are their presence or worsening with voluntary movement (action dystonia), amelioration with "sensory tricks," continual movements all day long with relief during sleep, and the potential for the movements to develop postural deformities. ${ }^{5}$ Pain is usually not a feature, but can occur in an occasional patient, and is most

Address for reprint requests: Dr Stanley Fahn, Neurological Institute, 710 West 168th Street, New York, NY 10032, USA.

Accepted January 1988 common in patients with torticollis. The pain appears to be a reflection of muscle contractions because it is relieved by injections of botulinum toxin at the site of the pain. ${ }^{67}$ The above typical features can be called classical torsion dystonia. When patients have features that run contrary to the above typical features, it seems appropriate to label such dystonic states as clinical variants of torsion dystonia. These variants refer to idiopathic torsion dystonia, and do not apply to symptomatic dystonia, which may be associated with other neurological abnormalities and which are caused by a great variety of environmental conditions and degenerative disorders. ${ }^{58}$ By the very nature of cerebral injury from these aetiologies, the appearance of dystonia can be highly variable and atypical for classical idiopathic torsion dystonia.

Aetiology is only one of three parameters by which dystonia is usually classified. The others are age at onset and distribution of dystonic involvement on the body. The latter provides the designations focal, segmental, generalised, multifocal, and hemidystonia ${ }^{4}$ The relationships of the different distributions with each other have been discussed elsewhere. ${ }^{5}$ The younger the age at onset, the more likely for dystonia to spread to involve other sites of the body and to become more severe. ${ }^{90}$ In contrast, the older the age at onset, the more likely dystonia will remain limited to a single region of the body. "Although age at onset and site of onset ${ }^{12}$ influence the final clinical state, this variability is standard and typical in classical dystonia.

The clinical variants to be discussed are paradoxical dystonia, paroxysmal dystonia, paroxysmal hypnogenic dystonia, diurnal dystonia, myoclonic dystonia, dystonic tics, and the pharmacologic-specific types 
dopa-responsive dystonia and alcohol-responsive dystonia, which overlap with diurnal and myoclonic dystonia, respectively. Not included are tardive dystonia $^{13}$ (a variant of tardive dyskinesia, but closely resembling torsion dystonia, ${ }^{14}{ }^{15}$ psychogenic dystonia, ${ }^{16}$ and dystonia that occurs due to Parkinsonism since these are part of the spectrum of the symptomatic dystonias. Idiopathic dystonia that precedes Parkinson's disease, however, appears to be a manifestation of classical dystonia, ${ }^{17-19}$ and at the moment is not considered a clinical variant.

\section{Paradoxical dystonia}

In patients with classical idiopathic dystonia, the involuntary movements are almost always aggravated during voluntary movement. If the movements appear only with voluntary movement, they are labelled "action dystonia." Idiopathic dystonia commonly begins with a specific action dystonia, that is, the abnormal movements appear with a special action and are not present at rest. To give an example, a child who develops idiopathic dystonia may have the initial symptom in one leg, but only when walking forward. It could be absent when running or walking backwards. As the dystonic condition progresses, less specific actions of the affected leg may activate the dystonia, such as when tapping the floor. With further worsening of the disorder, actions in other parts of the body can induce dystonic movements of the involved leg, socalled "overflow." With still further worsening, the affected limb can develop dystonic movements while it is at rest. Eventually the leg can have sustained posturing. Thus, dystonia at rest is considered a more advanced form compared to pure action dystonia. One of the most common forms of action dystonia is writer's cramp, a dystonia of the arm when used for the task-specific activity of writing. ${ }^{20}$ Playing a musical instrument is another fairly common task that is associated with action dystonia. Many times the dystonic movements are so rhythmic that distinguishing them from action tremor can sometimes be difficult, and the term dystonic tremor is appropriately applied. $^{21} 22$

Some forms of dystonia, however, appear to be suppressed with voluntary movement. This is particularly the case in blepharospasm, in which about $60 \%$ of patients have lessening of the facial contractions when they speak, whistle or hum. ${ }^{23}$ However, in other types of dystonia, either focal or generalised, it is rare for dystonia to be present at rest and disappear with action. When it occurs, the patient is constantly moving the affected body part in a continuous attempt to suppress the constant contractions. Two examples of personally observed patients serve to illustrate the clinical situation. The first is a woman with paradoxical torticollis, where the forceful head turning appears maximally when the patient is at rest sitting or lying, and disappears when she walks about or when she uses her hands constantly to knit. Because these activities suppress the torticollis, she has become a victim to ceaseless knitting. Another example is a patient with hand dystonia at rest that is suppressed by constantly and purposefully moving that affected hand. Voluntary movements of other parts of the body have no effect on the hand dystonia. It is not clear whether such paradoxical dystonia has a different pharmacologic profile from classical dystonia. In the two patients cited above, their response to anticholinergics and other medications has been unimpressive, but many more patients need to be studied in order to determine the pharmacologic profile.

\section{Paroxysmal dystonia}

When dystonic movements or postures are not continuous but occur paroxysmally followed by a return to normality with no neurological deficit between attacks, these are referred to as paroxysmal dystonic choreoathetosis or preferably as paroxysmal dystonia. The paroxysmal dystonias are commonly classified into two categories, kinesigenic and nonkinesigenic. ${ }^{24}$ In the kinesigenic type, the abnormal movements last seconds to minutes, and are usually easy to control with anticonvulsants. Although these kinesigenic dyskinesias are often choreic or ballistic in type, the abnormal movements can also be sustained and twisting in nature, thus satisfying the criteria as a dystonic movement.

Attacks of nonkinesigenic paroxysmal dystonia are not induced by sudden voluntary movement, but by fatigue after exercise, alcohol, coffee and stress. The duration of these bursts last minutes to hours, much longer than the seconds of the kinesigenic type. The disorder is usually reported as being familial, ${ }^{24}$ although non-familial cases are probably more common. ${ }^{25}$ Although the attacks are not induced by sudden voluntary movement, Marsden and his colleagues reported that sometimes prolonged exercise can trigger them. ${ }^{26}$ They also showed that exercise can also induce symptomatic paroxysmal dystonia. ${ }^{27}$ Prolonged exercise and fatigue can also exacerbate classical idiopathic dystonia, and may be the first hint of future development of this disorder.

The diagnosis of organic nonkinesigenic paroxysmal dystonia is one of the most difficult diagnoses to establish with certainty. It is usually extremely difficult to distinguish it from psychogenic paroxysmal dystonia. ${ }^{1625}$ The presence of clinical clues, such as fake weakness, somatisations, and deliberate slowness of movement, serve to lead one to the diagnosis of psychogenic dystonia. Other details to aid the clinician in establishing the correct diagnosis are provided elsewhere. ${ }^{16}$ If nonkinesigenic paroxysmal dystonia is 
familial, one can more readily accept the diagnosis of an organic, rather than a psychogenic, disorder. It is important to realise that a high percentage of cases with psychogenic dystonia appear as a paroxysmal disorder, so one must be suspicious of the possibility of this etiology when patients with paroxysmal nonkinesigenic dystonia are encountered.

Although some patients may respond to anticholinergics, ${ }^{28}$ nonkinesigenic paroxysmal dystonia usually does not respond to the same pharmacologic agents shown to be effective in classical torsion dystonia, ${ }^{29}$ which, in addition to the lack of continuous dystonia, makes a distinction between the two disorders. Pharmacologic agents that have been useful in nonkinesigenic paroxysmal dystonia are clonazepam, acetazolamide, and ACTH; carbamazepine has provided mixed results, sometimes beneficial and sometimes aggravating. ${ }^{25}$

\section{Paroxysmal hypnogenic dystonia}

A much less common form of paroxysmal dystonia is the type that develops during sleep, so-called paroxysmal hypnogenic dystonia. First described by Lugaresi and Cirignotta ${ }^{30}$ in 1981, there have been only a few subsequent reports of additional cases. ${ }^{31-36}$ So distinct is its usual feature of occurring during sleep that it deserves to be placed in its own category. It can be familial ${ }^{32}$ or sporadic.

Several episodes of brief attacks ( $15 \mathrm{~s}$ to $2 \mathrm{~min}$ ) can occur each night and can awaken the patient. Some patients may have longer duration attacks (lasting up to 1 hour). The attacks occur during non-REM sleep, and follow EEG signs of arousal, without epileptic discharges. Not all involuntary movements occurring in this syndrome are necessarily dystonia. The attack usually begins with the patient opening his eyes and then developing dystonic posturing or brisk shaking movements. The dystonic posturing appears to be sustained extension or flexion posturing rather than twisting. Daytime attacks while awake can occur on occasion. Seizures occur in a majority of patients.

In a recent report, ${ }^{36}$ episodes could also be induced by a tactile stimulus. Although not yet established, the reflex nature of the disorder in this most recent case may link it with other reflex dyskinesias, such as the hyperekplexias. ${ }^{37}$ Some patients may improve with carbamazepine, phenytoin, or amitriptyline.

\section{Dystonic tics}

Dystonic movements can also appear as motor tics, and these should be distinguished from the abnormal movements in classical dystonia. Dystonic tics are more appropriately classified in the tic category of abnormal involuntary movements than in the category of dystonia. Whereas classical dystonia, when it appears at rest, is a disorder in which the abnormal movements are continual, tics appear as a sudden abnormal movement on a background of normal motor behaviour. Motor tics can be either simple or complex patterned movements, and they are not continual unless they are severe. Usually they are very rapid and transient. But sometimes the tic movements have sustained posturing. Meige and Feindel ${ }^{38}$ called these prolonged posturings tonic tics, in contrast to the more common clonic tics. The tendency today is to use the term dystonic tics to refer to such tonic tics. Dystonic tics, like clonic tics, can often be suppressed voluntarily for a short period of time. In support of the concept that dystonic tics should be classified as a tic disorder is that they may also be associated with other forms of tics, such as phonations, complex patterned movements, and clonic tics.

However, when dystonic tics appear as an isolated motor phenomenon, it may be difficult to determine if one is dealing with dystonic tics or idiopathic torsion dystonia. This is particularly the case with eye blinking and other facial movements. Although the cranial region is the most common part of the body affected with tics, focal and segmental dystonia also frequently occurs in this area, such as blepharospam. ${ }^{39}$ Therefore, this form of cranial sustained movements can resemble both dystonia and tics. Fortunately, the age at onset of a tic disorder is usually in the childhood years, whereas the onset of blepharospasm is in adult life. However, in other parts of the body, dystonia appears at a youngerO age at onset, so the differential diagnosis becomes more difficult. The most helpful approach in the differential diagnosis is to distinguish the two disorders by the company they keep. Dystonic tics tend $\cong$ to be associated with other phenomenology of tics. A complicating factor, however, is that tics may be present in patients who have idiopathic torsion dystonia,${ }^{40}$ and then dystonic tics may not be possible to separate from idiopathic dystonia unless they are voluntarily suppressible or the patient recognizes an urge to make the tic movement.

\section{Myoclonic dystonia}

The speed of dystonic movements varies from slow to rapid, more often the latter. The speed can be so fast that they have the appearance of repetitive myoclonic jerking. Beginning with Davidenkow in $1926,{ }^{41}$ the term myoclonic dystonia has been applied to such type of dystonia. When the term was used by Obeso et al, ${ }^{42}$ it was intended to emphasise that since shock-like movements are not uncommon in dystonia, the disorder with both sustained and shock-like movements should still be called dystonia. Unless the accompanying dystonia is also recognised, such patients may be, and often are, incorrectly designated as cases of myoclonus. It was because of this concern that Obeso 
et $a l^{42}$ drew attention to the problem and reintroduced the term myoclonic dystonia.

This matter was complicated further by the recognition of a subgroup of patients with idiopathic dystonia who exhibit the combination of shock-like jerks with dystonic spasms and postures, occurring in families with apparent autosomal dominant inheritance, and characteristically showing dramatic benefit with alcohol. ${ }^{434}$ The suggested designation of this entity was "hereditary dystonia with lightning jerks, responsive to alcohol." The exact relationship of this condition to hereditary essential myoclonus remains to be determined. But it seems reasonable at this point in time to consider this type of myoclonic dystonia as a distinct variant from classical idiopathic torsion dystonia.

\section{Diurnal dystonia}

Some patients, who otherwise satisfy the criteria of dystonia, may be relatively free of dystonic movements and postures in the morning and be afflicted severely in the late afternoon, evening and night. This temporal pattern has been considered a variant of dystonia and referred to as dystonia with marked diurnal variation by Segawa and colleagues. ${ }^{45}$ There are two other clinical features that highlight this disorder: many have features of Parkinsonism, ${ }^{46-48}$ including loss of postural reflexes with falling, and these patients respond remarkably well to low dosage levodopa ${ }^{45} 4649$ bromocriptine ${ }^{50}$ or anticholinergics. ${ }^{5152}$ This disorder appears to be inherited as an autosomal dominant. As shall be pointed out in the next section, diurnal dystonia is now considered a subtype of the clinical variant, dopa-responsive dystonia.

\section{Dopa-responsive dystonia}

The term dopa-responsive dystonia is used to designate the most recently described subgroup of idiopathic torsion dystonia. It is applied to those patients with dystonia who respond dramatically to very low dosage levodopa. ${ }^{53}$ This group is characterised as having onset of dystonia at age 16 years or younger, onset in the legs or with gait, and often having features of Parkinsonism, including loss of postural features. Thus, there is a link with juvenile Parkinsonism. ${ }^{54}$ This group appears to be inherited as autosomal dominant, with some members of the family manifesting dystonia only, others as Parkinsonism only, and others with combined features. ${ }^{55}$ The spectrum of dopa-responsive dystonia includes not only those presenting with dystonia of gait in that age group, but others with what appear to be a dystonic paraplegia, or a bizarre gait with unexplained falls. Dopa-responsive dystonia is probably more common than is generally appreciated, particularly among the non-Jewish dystonia population, and it may make up about $10 \%$ of all childhood-onset cases of idiopathic dystonia. Thus, children with dystonia should be given a trial of carbidopa/levodopa, up to $25 / 250 \mathrm{mg}$ q.i.d. before embarking on anticholinergics and other medications.

From the above description, one can recognise an overlap with diurnal dystonia, since this latter group is also characterised as having a marked beneficial response to levodopa. The concept proposed by Nygaard, Duvoisin and Marsden ${ }^{53}$ is that diurnal dystonia falls within the dopa-responsive dystonia group. One should not fail to consider doparesponsive dystonia simply because the patient does not have diurnal variation of symptoms.

There are some patients with adult-onset focal and cranial dystonias who also respond to the dopamine agonist, lisuride, but not bromocriptine. ${ }^{56}$ It is not clear if these patients would also respond to levodopa. This group of adult onset cranial dystonias is currently not considered as part of the category referred to as dopa-responsive dystonia.

\section{Conclusions}

A variety of patients with dystonic movements and postures not known to be caused by environmental or degenerative disorders can be segregated out from classical-appearing idiopathic torsion dystonia on the basis of distinctive clinical and pharmacologic features. Some of them should be considered within the family of dystonia, where others are better classified as being part of other families of dyskinesias. The table shows a convenient way to divide this group of disorders.

Table Classification of the clinical variants of idiopathic dystonia syndromes

\begin{tabular}{ll}
\hline Idiopathic torsion dystonia & Other dyskinesias \\
\hline Classical torsion dystonia & Dystonic tics \\
Paradoxical dystonia & Paroxysmal dystonia \\
Myoclonic dystonia & Hypnogenic dystonia \\
Diurnal dystonia & \\
Dopa-responsive dystonia & \\
\hline
\end{tabular}

In the future, as more detailed understanding of torsion dystonia is obtained, additional clinical variants of dystonia may be added to this list.

\section{References}

1 Oppenheim H: Uber eine eigenartige Krampfkrankheit des kindlichen und jugendlichen Alters (Dysbasia lordotica progressiva, Dystonia musculorum deformans). Neurol Centrabl 1911;30: 1090-107.

2 Flatau E, Sterling W: Progressiver Torsionspasms bie Kindern. $Z$ Gesamte Neurol Psychiatr 1911;7:586-612.

3 Fahn S. The varied clinical expressions of dystonia. Neurol Clin 1984;2:541-54. 
4 Fahn S. Concept and classification of dystonia. Adv Neurol 1988; 50:1-8.

5 Fahn S, Marsden CD, Calne DB. Classification and investigation of dystonia. In: Marsden CD, Fahn S, eds: Movement Disorders 2. London, Butterworths, 1987:332-358.

6 Brin MF, Fahn S, Moskowitz C, et al. Localized injections of botulinum toxin for the treatment of focal dystonia and hemifacial spasm. Movement Disorders 1987;2:237-54.

7 Jankovic J. Blepharospasm and oromandibular-laryngeal-cervical dystonia: A controlled trial of botulinum A toxin therapy. $A d v$ Neurol 1988;50:583-91.

8 Calne DB, Lang AE. Secondary dystonia. Adv Neurol 1988;50: 9-33.

9 Marsden CD, Harrison MJG, Bundey S. Natural history of idiopathic torsion dystonia. Adv Neurol 1976;14:177-87.

10 Fahn S. Generalised dystonia: concept and treatment. Clin Neuropharmacol 1986;9:Suppl 2:S37-S48.

11 Marsden CD. The focal dystonias. Clin Neuropharmacol 1986; 9:Suppl 2:S49-S60.

12 Greene P, Fahn S. Patterns of spread of dystonia in childhood onset dystonia. Neurology 1987;37(Suppl 1):269.

13 Burke RE, Fahn S, Jankovic J, et al. Tardive dystonia: Late-onset and persistent dystonia caused by antipsychotic drugs. Neurology 1982;32:1335-46.

14 Fahn S. The tardive dyskinesias. In Matthews WB, Glaser GH, eds: Recent Advances in Clinical Neurology, Edinburgh, Churchill Livingstone, 1984;4:229-60.

15 Kang UN, Burke RE. Natural history and treatment of tardive dystonia. Movement Dis 1986;1:193-203.

16 Fahn S, Williams DT. Psychogenic dystonia. Adv Neurol 1988; 50:431-55.

17 LeWitt PA, Burns RS, Newman RP. Dystonia in untreated Parkinsonism. Clin Neuropharmacol 1986;9:293-7.

18 Klawans HL, Paleologos N. Dystonia-Parkinson syndrome: differential effects of levodopa and dopamine agonists. Clin Neuropharmacol 1986;9:298-302.

19 Katchen M, Duvoisin RC. Parkinsonism following dystonia in three patients. Movement Disorders 1986;1:151-157.

20 Sheehy MP, Marsden CD. Writer's cramp—a focal dystonia. Brain 1982;105:461-80.

21 Cohen LG, Hallett M, Sudarsky L. A single family with writer's cramp, essential tremor, and primary writing tremor. Movement Disorders 1987;2:109-16.

22 Rosenbaum F, Jankovic J. Focal task-specific tremor and dystonia: Categorisation of occupational movement disorders. Neurology 1988;38:522-7.

23 Fahn S, Hening WA, Bressman S, Burke R, Ilson J, Walters A: Long-term usefulness of baclofen in the treatment of essential blepharospasm. Advances in Ophthalmic Plastic Reconstructive Surgery 1985;4:219-226.

24 Lance JW. Familial paroxysmal dystonic choreoathetosis and its differentiation from related syndromes. Ann Neurol 1977;2: 285-93.

25 Bressman SB, Fahn S, Burke RE. Paroxysmal non-kinesigenic dystonia. Adv Neurol 1988;50:403-13.

26 Plant GT, Williams AC, Earl CJ, Marsden CD. Familial paroxysmal dystonia induced by exercise. J Neurol Neurosurg Psychiatry 1984;47:275-9.

27 Berardelli A, Thompson PD, Day BL, Rothwell JC, O'Brien MD, Marsden CD. Dystonia of the legs induced by walking or passive movement of the big toe in a patient with cerebellar ectopia and syringomyelia. Neurology 1986;36:40-44.

28 Micheli F, Pardal MF, de Arbelaiz R, Lehkuniec E, Giannaula R. Paroxysmal dystonia responsive to anticholinergic drugs. Clin Neuropharmacol 1987;10:365-9.

29 Greene P, Shale H, Fahn S. Analysis of open-label trials in torsion dystonia using high dosages of anticholinergics and other drugs. Movement Disorders 1988;3:46-60.

30 Lugaresi E, Cirignotta F. Hypnogenic paroxysmal dystonia: epileptic seizure or a new syndrome? Sleep 1981;4:129-38.
31 Rajna P, Kundra O, Halasz P. Vigilance level-dependent tonic tonic seizures: epilepsy or sleep disorder? A case report. Epilepsia 1983;24:725-33.

32 Lee BI, Lesser RP, Pippenger CE, Morris HH, Luders H, Dinner DS, Corrie WS, Murphy WF. Familial paroxysmal hypnogenic dystonia. Neurology 1985;35:1357-60.

33 Godbout R, Montplaisir, Rouleau I. Hypnogenic paroxysmal dystonia: epilepsy or sleep disorder? A case report. Clin Electroencephalogr 1985;16:136-142.

34 Crowell JA, Anders TF. Hypnogenic paroxysmal dystonia. J Am Acad Child Psychiatry 1985;24:353-8.

35 Lugaresi E, Cirignotta F, Montagna P. Nocturnal paroxysmal dystonia. J Neurol Neurosurg Psychiatry 1986;49:375-80.

36 Lehkuniec E, Micheli F, de Arbelaiz R, Torres M, Paradiso G. Concurrent hypnogenic and reflex paroxysmal dystonia. Movement Disorders 1988;3:290-4.

37 Andermann F, Andermann E. Excessive startle syndromes: startle disease, jumping, and startle epilepsy. Adv Neurol 1986;43: 321-38.

38 Meige H, Feindel E. Tics and Their Treatment. Translated from the French by Wilson SAK. London, Appleton, 1907.

39 Fahn S. Blepharospasm: A form of focal dystonia. Adv Neurol 1988;49:125-33.

40 Shale HM, Truong DD, Fahn S: Tics in patients with other movement disorders. Neurology 1986;36(Suppl 1): 118 .

41 Davidenkow S. Auf hereditar-abiotrophischer Grundlage akut auftretende, regressierende und episodische Erkrankungen des Nervensystems und Bemerkungen uber die familiare subakute, myoklonische Dystonie. Z ges Neurol Psychiat 1926;104: 596-622.

42 Obeso JA, Rothwell JC, Lang AE, Marsden CD. Myoclonic dystonia. Neurology 1983;33:825-30.

43 Kurlan R, Behr J, Medved L, Shoulson I. Myoclonus and dystonia: A family study. Adv Neurol 1988;50:385-9.

44 Quinn NP, Rothwell JC, Thompson PD, Marsden CD. Hereditary myoclonic dystonia, hereditary torsion dystonia and hereditary essential myoclonus: An area of confusion. Adv Neurol 1988 50:391-401.

45 Segawa M, Hosaka A, Miyagawa F, Nomura Y, Imai H Hereditary progressive dystonia with marked diurnal fluctuation. Adv Neurol 1976;14:215-33.

46 Nygaard TG, Duvoisin RC. Hereditary dystonia-parkinsonism syndrome of juvenile onset. Neurology 1986;36:1424-28.

47 Segawa M, Nomura Y, Tanaka S, Hakamada S, Nagata E, et al. Hereditary progressive dystonia with marked diurnal fluctuation-consideration on its pathophysiology based on the characteristics of clinical and polysomnographical findings. $A d v$ Neurol 1988;50:367-76.

48 Sunohara N, Mano Y, Ando K, Satoyoshi E. Idiopathic dystoniaparkinsonism with marked diurnal fluctuation of symptoms. Ann Neurol 1985;17:39-45.

49 Deonna T. DOPA-sensitive progressive dystonia of childhood with fluctuations of symptoms: Segawa's syndrome and possible variants. Neuropediatrics 1986;17:81-85.

50 Sabouraud O, Allain H, Pinel JF, Menault P. Famialiale transformee par la bromocriptine. Nouv Presse Med 1978;7:3370.

51 Corner BD. Dystonia musculorum deformans in siblings treated with Artane (trihexyphenidyl). Proc $R$ Soc Med 1952;45:451-2

52 Burns CLC: The treatment of torsion spasm in children with trihexyphenidyl (Artane). The Medical Press 1959;241:148-9.

53 Nygaard TG, Marsden CD, Duvoisin RC. Dopa-responsive dystonia. Adv Neurol 1988;50:377-84

54 Rondot $\mathbf{P}$, Ziegler $M$. Dystonia-levodopa responsive or juvenile parkinsonism? J Neural Transm Suppl 1983;19:273-81.

55 de Yebenes JG, Moskowitz C, Fahn S, Saint-Hilaire MH. Longterm treatment with levodopa in a family with autosomal dominant torsion dystonia. Adv Neurol 1988;50:101-11.

56 Micheli F, Fernandez-Pardal MM, Leiguarda RC. Beneficial effects of lisuride in Meige disease. Neurology 1982;32:432-4. 